\title{
Samango Monkeys (Cercopithecus albogularis labiatus) Manage Risk in a Highly Seasonal, Human-Modified Landscape in Amathole Mountains, South Africa
}

\author{
Katarzyna Nowak ${ }^{1,2}$ - Kirsten Wimberger ${ }^{3}$. \\ Shane A. Richards ${ }^{4}$ - Russell A. Hill ${ }^{1}$ - Aliza le Roux ${ }^{2}$
}

Received: 28 January 2016 / Accepted: 7 July 2016/Published online: 19 August 2016

(C) The Author(s) 2016. This article is published with open access at Springerlink.com

\begin{abstract}
Wild species use habitats that vary in risk across space and time. This risk can derive from natural predators and also from direct and indirect human pressures. A starving forager will often take risks that a less hungry forager would not. At a highly seasonal and human-modified site, we predicted that arboreal samango monkeys (Cercopithecus albogularis labiatus) would show highly flexible, responsive, risksensitive foraging. We first determined how monkeys use horizontal and vertical space across seasons to evaluate if high-risk decisions (use of gardens and ground) changed with season, a proxy for starvation risk. Then, during a subsequent winter, we offered equal feeding opportunities (in the form of high-value, raw peanuts) in both gardens and forest to see if this short-term change in food availability and starvation risk affected monkeys' foraging decisions. We found that during the food-scarce winter, monkeys foraged outside indigenous forest and in gardens, where they fed on exotic species, especially fallen acorns (Quercus spp.), despite potential threats from humans. Nevertheless, and as predicted, when given the choice of foraging on high-value foods in gardens vs. forest during our artificial foraging experiment, monkeys showed a preference for a safer forest habitat. Our experiment also indicated monkeys' sensitivity
\end{abstract}

Electronic supplementary material The online version of this article (doi:10.1007/s10764-016-9913-1) contains supplementary material, which is available to authorized users.

Katarzyna Nowak

knowak02@gmail.com

1 Evolutionary Anthropology Research Group, Durham University, Durham DH1 3LE, UK

2 Zoology and Entomology, University of the Free State, Qwaqwa Campus, Phuthaditjhaba 9866, South Africa

3 Biological Sciences, University of Cape Town, Rondebosch 7701, Cape Town, South Africa

4 Commonwealth Scientific and Industrial Research Organisation, Canberra, ACT 2600, Australia 
to risk in the lower vertical strata of both habitats, despite their previous extensive use of the ground. Our findings support one of the central tenets of optimal foraging theory: that risk of starvation and sensitivity to the variation in food availability can be as important drivers of behavior as risk of predation.

Keywords Cercopithecus mitis · Giving-up density · Human disturbance · Landscape of Fear $\cdot$ Guenon

\section{Introduction}

Animals do not use landscapes equally across time and space, with their movements generally influenced by a combination of food availability, habitat features, and predation risk (Coleman and Hill 2014; Druce et al. 2009; Makin et al. 2012; Stears and Shrader 2015; Willems and Hill 2009). A food patch is chosen on the basis of a trade-off between feeding rate and predation risk (Brown 1999). Although areas of high predator density or human disturbance are generally avoided (Abu Baker et al. 2015; Brown and Kotler 2004; Makin et al. 2012), a starving forager will often take risks that a less hungry forager would not, based on the economic calculation that certain death by starvation is more risky than possible death from predation (Brown and Kotler 2007; Dill and Fraser 1984).

People profoundly affect the ways in which wild animals assess risk (Coleman et al. 2008; Nowak et al. 2014) and distribute themselves across space (Blumstein 2014; Frid and Dill 2002; Tadesse and Kotler 2012). For example, the effects of humans on the foraging and vigilance behavior of elk (Cervus elephus) were found to surpass those of both natural predators and habitat type (Ciuti et al. 2012). Likewise, Nubian ibex (Capra nubiana) left more food uneaten at artificial foraging stations during weekends when human visitation to a national park was high, suggesting that ibex respond to humans as they would to a predator (Tadesse and Kotler 2012). Contrarily, opportunistic mammals such as baboons (Papio spp.) may be attracted to human-occupied areas because of the potential resources they offer (Hoffman and O'Riain 2011; Strum 2010) or the safety from natural predators they confer (Berger 2007). Such risky behavior can be motivated by the scarcity of wild fruits (Hockings et al. 2009; Wimberger et al. in prep.); for example, chimpanzees (Pan troglodytes) in Bossou, Guinea, take risks to consume cultivars, especially sugar fruits at certain times of year (Hockings and McLennan 2012). The strength of an animal's behavioral response to human presence is patently related to its condition (Beale and Monaghan 2004) and, as thirst or hunger and risk of starvation increase, animals will select more hazardous foraging sites and engage in riskier behavior (Sih 1980; Verdolin 2006).

The relative riskiness of an area can be quantified in both time and space. Artificial foraging experiments in the form of giving-up densities (GUDs) help estimate the point at which an animal stops foraging as the risk of predation and lost opportunity costs outweigh energetic gains (Brown 1988). GUDs have been effectively used to gauge the perceived risk and habitat preferences of rodents (Brown 1988), ungulates (Stears and Shrader 2015; Tadesse and Kotler 2012), and primates (Emerson and Brown 2013; Emerson et al. 2011; Makin et al. 2012; Nowak et al. 2014). This technique allows researchers to go beyond the binary classification of "high-risk" and "low-risk" areas, 
highlight the relative degree of risk faced in different parts of an animal's microhabitat, and take seasonal changes into account as well.

We aimed to examine how a group of arboreal monkeys perceives the threat imposed by humans and human infrastructure when food availability is seasonally low at the southern limit of their range in Hogsback, Eastern Cape, South Africa (Lawes 1990). Samango monkeys (Cercopithecus albogularis labiatus: Dalton et al. 2015)) are endemic to South Africa, where they are Red-Listed as Vulnerable (Linden et al. 2016), having declined by $>30 \%$ in the past ca. $30 \mathrm{yrs}$ and now confined to remaining forest fragments (Lawes 2008). At Hogsback, samango monkeys inhabit a human-modified habitat in which they frequent a village and gardens to feed on the seeds of exotic oaks (Quercus spp.) and black wattle (Acacia sp.) (Wimberger et al., in prep.) where humans (who chase and shoot monkeys) and domestic dogs (which chase and bite monkeys) pose the major threats to monkeys. Using behavioral data, we first examined how monkeys use horizontal space (residential gardens vs. indigenous Afromontane forest) and vertical space (ground vs. tree level) across four distinct seasons. In this way we evaluated if high-risk decisions (use of gardens and ground) changed with season, a proxy for starvation risk. Few researchers get the opportunity to change this economic calculation for their study subjects. During a subsequent winter, we offered equal feeding opportunities in both gardens and forest to assess monkeys' relative perceived risk and patch use with a GUD experiment. We predicted that 1) arboreal monkeys perceive gardens and the ground to be riskier than indigenous forest and the tree canopy; 2) monkeys will use gardens and the ground more extensively during winter, when forest food availability is relatively lower; and 3) given equal feeding opportunities in both habitats (gardens and forest) during winter, monkeys will demonstrate a flexible, opportunistic foraging strategy and show a preference for the less risky indigenous forest.

\section{Methods}

\section{Study Site}

Hogsback lies in the Amathole Mountain range $\left(32^{\circ} 35^{\prime} \mathrm{S}, 26^{\circ} 56^{\prime} \mathrm{E}\right)$ in the Eastern Cape province of South Africa (Fig. 1) at ca. $1200 \mathrm{~m}$ a.s.l. The village consists of large residential gardens planted primarily with exotic plant species including oak (especially Quercus robur and Q. palustris) and black wattle (Acacia mearnsii). The village is surrounded by indigenous, primarily southern mistbelt forest and commercial plantations of exotic pine (Pinus sp.). Mean annual rainfall is 1029 $( \pm 170 \mathrm{SD}, N=3$ years $) \mathrm{mm}$ (Webster, unpubl. data) and temperatures fall from $29.6( \pm 2.2 \mathrm{SD}){ }^{\circ} \mathrm{C}$ in summer to $5.7( \pm 1.2 \mathrm{SD}){ }^{\circ} \mathrm{C}$ in winter, when it usually snows (SAWS 2011 unpubl. data).

Apart from a pair of resident crowned eagles (Stephanoaetus coronatus), risk from natural predators such as leopards (Panthera pardus) is low because of human-induced changes to natural habitat and hunting and trapping of predators in surrounding cattle and sheep farming areas. Anthropogenic risks to samango monkeys are high and include risk of injury and death by domestic dogs in 


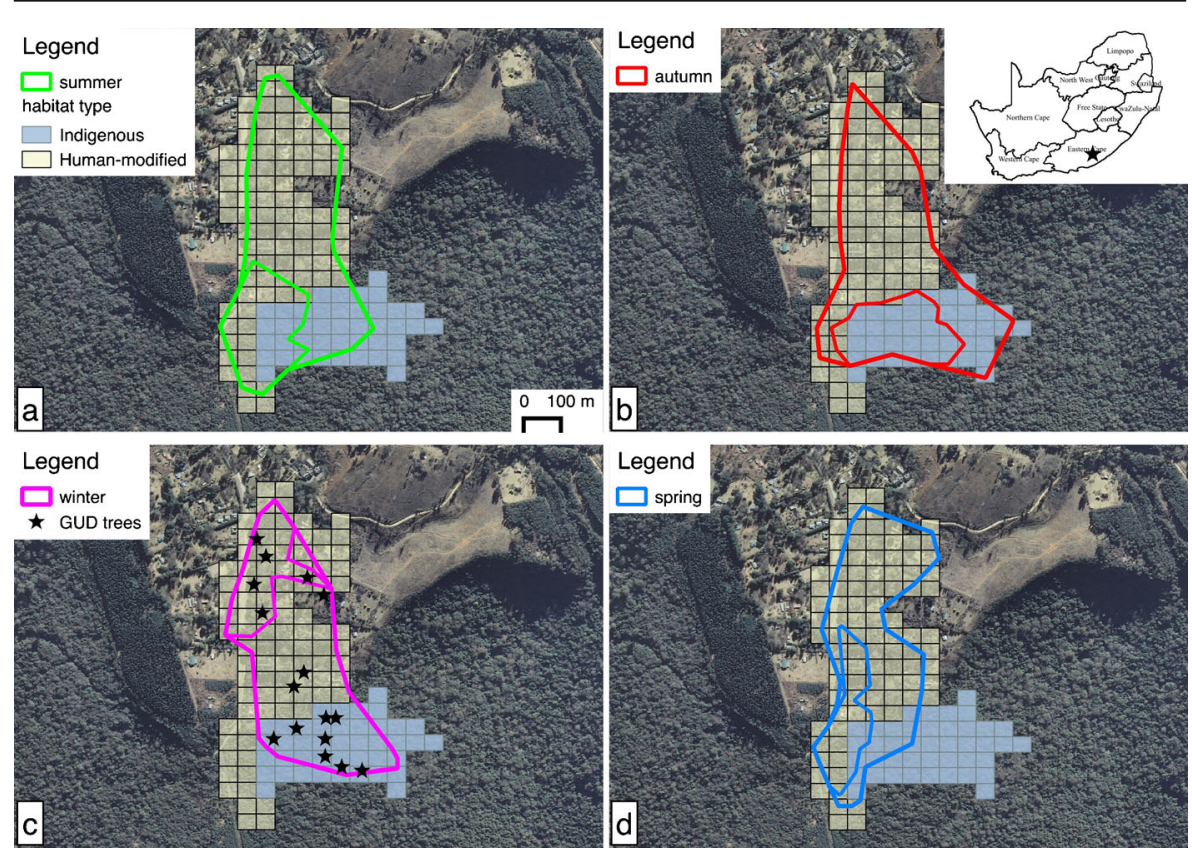

Fig. 1 Polygons represent monkeys' maximum and core ranges (100\% and $50 \%$ isopleths) for each season with green (a) =summer, red (b) =autumn, pink (c) =winter, blue (d) =spring. Stars indicate locations of GUD patches that were established at random points generated inside $100 \%$ of the monkeys' winter range. (Note: the GUD experiment took place only in a subsequent winter.) The grid shows the total annual home range where off-white cells indicate human-modified habitat (including parts of Hogsback village) and light blue indicates indigenous forest

residential properties, persecution by landowners when monkeys eat from orchards and even houses, and electrocution along powerlines used by monkeys to navigate the gardens' discontinuous canopy. Conflict between human and nonhuman primates (chacma baboons [Papio ursinus] and samango monkeys) has escalated over recent years, with perceived increases in boldness, aggression, and population size of samango monkeys as well as growing overlap between samango monkey home ranges and residential properties (Wimberger pers. obs.; Wimberger and Bidner 2012). Although some attempts have been made to raise the awareness of people in Hogsback about samango monkey behavior and ways to coexist with them, e.g., by securing vegetable gardens (Wimberger and Bidner 2012), some residents have recently made calls to the provincial nature conservation agency for help with managing "the samango problem."

\section{Study Groups}

An estimated eight samango monkey groups inhabit Hogsback village and adjacent forests (Wimberger unpubl. data). We focused on one group (ca. 35 individuals), whose home range spanned both residential gardens in Hogsback village and intact indigenous state forest. This group had never before been exposed to any field experiments. 


\section{Annual Ranging Patterns and Ground Use}

We followed the study group for 35 d over 12 mo (February 1, 2011-January 31, 2012), for a total of 386.8 observation hours, split into summer (6 d during February 2011, December 2011, January 2012), autumn (9 d, March-May 2012), winter (11 d, June-August 2012), and spring (9 d, September-November 2012) for analyses. During full-day (dawn until dusk) follows, we used instantaneous scan sampling at intervals of $10 \mathrm{~min}$ to record the activity, diet (presented in Wimberger et al. in prep.), and the estimated height above ground of as many individuals as possible within a 5-min period. Estimated height above ground was later categorized as "ground" (0-2 $\mathrm{m})$ or "tree" (>2 m) to compare with our GUD experiment (see later). We also recorded the group's location every $30 \mathrm{~min}$ standing at the group center with a hand-held GPS (Dakota 20, Garmin Inc., USA).

We projected movement data ( $N=230$ in winter, 228 in spring, 161 in summer, 197 in autumn) in UTM Zone 35S, spheroid WGS 1984 before analyses. We used Fixed $k$ Local Convex Hull (LoCoH, 2005. Wayne Getz lab. http://locoh.cnr.berkeley.edu/) to determine $100 \%$ and $50 \%$ (core) seasonal home ranges, because this method takes into account geomorphological boundaries such as roads (Getz et al. 2007). We used a $k$ of 40, and duplicate points were displaced by one unit, i.e., in a random direction by $1 \mathrm{~m}$, for analyses. We also determined the average mean daily distance moved by each group by calculating the distance between successive GPS positions using the Home Range Tools extension version 1.1 (Rodgers et al. 2007) for ESRI ${ }^{\circledR} \operatorname{ArcMap}^{\mathrm{TM}}$ 9.3.1 (Esri 2008), which was then summed for each day. Where data points were missing (maximum of four data points), we calculated the distance from the last point recorded and the results thus show the minimum distance traveled each day. Using Hawth's Analysis Tools 3.27 (Beyer 2004) extension for ESRI ${ }^{\circledR} \operatorname{ArcMap}^{\mathrm{TM}}$ 9.3.1, we overlaid a grid on the GPS data points. A grid cell size of $50 \times 50 \mathrm{~m}$ was chosen based on an estimate of mean group spread. For analysis of relative habitat use by each group, we labeled each cell as either "indigenous" or "human-modified" based on whether indigenous or exotic plants were dominant $(>50 \%)$ as determined through visual assessment based on satellite imagery and on the ground confirmation using resource abundance transects. We established these transects ( $100 \mathrm{~m}$ long with a width of $5 \mathrm{~m}$ on either side) throughout the home range of the group, and recorded the species, height, and diameter at breast height $(\mathrm{DBH})$ of all trees with $>5 \mathrm{~cm} \mathrm{DBH}$ (Wimberger et al. in prep.).

\section{Experimental Food Patches in Forest and Gardens During Winter}

We carried out the GUD experiment in winter $3 \mathrm{yr}$ after behavioral and ranging data were collected, from May until July 2014. This was the food-scarce season (Wimberger et al. in prep.) when we would predict monkeys to take risks unless other options are available. We first generated 16 random points in QGIS (2.4.0. Chugiak, http://qgis.org, $\mathrm{http}$ //creativecommons.org/licenses/by-sa/3.0/) in the winter range of the study group (based on $100 \%$ isopleth). We established eight experimental (GUD) food patches in exotic gardens and eight in indigenous forest (Fig. 1c, black asterisks on winter map). Food patches were established in a way consistent with previous GUD work on samango monkeys (Cercopithecus albogularis schwarzi) conducted in the Sout 
pansberg Mountains, Limpopo Province (Nowak et al. 2014). At each of the 16 locations, we suspended one plastic basin at each of the four heights, namely at the ground $(0.1 \mathrm{~m})$ to tree level at $2.5 \mathrm{~m}, 5 \mathrm{~m}$, and $7.5 \mathrm{~m}$, such that there were 64 experi mental basins in total.

Before the experiment, we carried out 2 weeks of habituation, giving monkeys time to learn the location of the patches. In week 1, monkeys had access for 4 consecutive days to empty basins containing unshelled whole peanuts and orange quarters (used as extra incentive to draw monkeys in to the experimental area). In week 2 , we increased the difficulty by restricting their access to the basins by weaving ropes along the top of the basins to slow foraging rate. We needed to influence the foraging rate so that monkeys would leave some food and we would have data on how much monkeys "gave up," i.e., GUDs. During this week 2, we had $2 \mathrm{~d}$ when basins were filled with shelled whole peanuts and $1 \mathrm{~L}$ of sawdust and two ropes along the top and 2 days with halved peanuts in $2 \mathrm{~L}$ of sawdust with six ropes along the top. We then carried out $20 \mathrm{~d}$ of GUDs ( $4 \mathrm{~d}$ /week over 5 weeks) with 25 raw peanut halves mixed into 4 L of sawdust and a complex 12-cell grid of ropes along the top of the basin. GUD was the number of peanuts remaining at the end of each experimental day $(16: 00 \mathrm{~h})$ and represented the extent to which patches were depleted. We analyze data from only these 20 experimental days.

\section{Analysis}

We used nonparametric Kruskal-Wallis tests to examine seasonal differences in the time monkeys spent in gardens (fraction of total number of GPS points recorded during behavioral follows), and daily distance traveled. Post hoc tests were done on pairwise comparisons between seasons using the Tukey and Kramer (Nemenyi) test with Tukey-Dist approximation for independent samples data.

We fit a generalized linear mixed model (GLMM) with a logit link function and a binomial error distribution to the foraging data describing seasonal variation in ground use and a likelihood ratio test (LRT) used to test for seasonal differences. Though we retained the four basin heights in our analyses, we focused on two height categories: "ground" and "tree," as our interest was to determine when arboreal monkeys would visit the risky ground vs. being safer on a tree, with $2 \mathrm{~m}$ representing a height where dogs and humans are unlikely to reach. Furthermore, a similar GUD experiment on a northern population of samango monkeys Cercopithecus albogularis schwarzi (Nowak et al. 2014) suggested that the biggest differences observed in GUDs were between experimental basins placed at ground vs. tree level.

We investigated the GUD data using GLMMs with a logit link function and a binomial error distribution. We considered basin height to be a covariate and location to be a fixed factor with two categories: gardens and forest. Our investigation of the data suggested that the role of day was best modeled as a random effect (Electronic Supplementary Materials), and we also included tree as a random effect. The GUD data were overdispersed with respect to the binomial distribution, so we accounted for this by including an additional random effect at the observation scale (Electronic Supplementary Materials). We used an LRT to test for an interaction between height and location. Finally, we used a GLMM 
(logit link function, binomial error distribution) and a LRT to compare rates of visitation between gardens and forest for our GUD experiment.

We performed all GLMM analyses in R 3.2.0 (R Core Team 2015) using the package lme4. When estimating uncertainty in our model predictions, we used bootstrapping to estimate $95 \%$ confidence intervals (CIs). A full description of the analyses can be found in the Electronic Supplementary Materials.

\section{Ethical Note}

Our research did not involve direct contact with monkeys during the behavioral follows or the GUD experiment. To limit potential pathogen transmission between researchers and monkeys, we used goggles and surgical masks to cover our faces when handling the food, and ensured we washed our hands before and after handling the food. Monkeys were "provisioned" only during this single and short experimental period, using the minimum number of peanuts needed to conduct the experiment, as there are possible negative implications of provisioning monkeys, including increased foraging in gardens and reduced fear of humans. The behavioral research (2010-2012) was approved by the National Zoological Gardens of South Africa's Research and Ethics Committee and the University of Fort Hare, while the GUD research was approved by the Life Sciences Ethical Review Process Committee and Anthropology Department's Ethics Subcommittee at Durham University and by the Interfaculty Animal Ethics Committee at the University of the Free State. Fieldwork was conducted with permission from the Department of Economic Development, Environmental Affairs and Tourism, and the Department of Agriculture, Forestry and Fisheries, Eastern Cape Province.

\section{Results}

\section{Annual Ranging Patterns Across Forest and Gardens}

Monkeys used residential gardens extensively (Fig. 1), but their use of gardens varied by season (Kruskal-Wallis $\chi^{2}=18.717$, $\mathrm{df}=3, N=820$ GPS points, $P<0.001$ ), with gardens being used significantly more in spring than in autumn $(P<0.001)$. If only core ranges (50\% isopleths) are examined (Fig. 1), the seasonal differences in range overlap with human-modified habitat and indigenous forest can be seen more clearly [KruskalWallis $\chi^{2}=253.21, \mathrm{df}=3, N=396$ GPS points, $P<0.001$, with winter distinct from autumn $(P<0.001)$ and summer $(P=0.027)$ but not spring $(P=0.891)$ in the extent to which monkeys used gardens vs. forest]. During spring (Fig. 1d) and summer (Fig. 1a), monkeys' core range included both human-modified habitat and indigenous forest, but in autumn (Fig. 1b) the group's core range spanned indigenous habitat only, whereas in winter (Fig. 1c), the monkeys' core range fell entirely inside gardens. The group's core ranges were the smallest in spring (4.24 ha) and largest (6.37 ha) in summer and similarly sized in winter (4.70 ha) and autumn (4.94 ha).

We found no significant differences in mean daily path lengths across seasons (Kruskal-Wallis $\chi^{2}=5.492, \mathrm{df}=3, N=33$ days, $P=0.139$ ) but the longest daily path 
length was in autumn $(1360 \pm 377 \mathrm{~m} \mathrm{SD})$, with the shortest in winter $(1065 \pm 234 \mathrm{~m}$ SD), compared with summer (1339 $\pm 189 \mathrm{~m} \mathrm{SD})$ and spring (1092 $\pm 144 \mathrm{~m} \mathrm{SD})$.

\section{Extent of Ground Use Across Seasons}

The extent to which monkeys used the ground differed across seasons (LRT, $G_{3}=21.20, P<0.001$; Fig. 2), with monkeys observed on the ground more frequently in winter, especially when compared with summer and autumn. Only in winter did monkeys spend more than a third of their time on the ground (Fig. 2).

\section{Relative Use of Food Patches in Forest vs. Gardens During Winter}

We found an interaction between habitat (forest vs. gardens) and basin height (ground vs. tree) when predicting GUDs (LRT; $G_{1}=4.55, P=0.033$ ). GUDs were higher on the ground compared with the three tree levels in both habitats, and higher in forest habitat, especially for basins placed near the ground (Fig. 3). Despite GUDs being slightly lower in garden trees, we found evidence that trees in the forest were more often visited (LRT, $G_{1}=7.62, P=0.006$; Fig. 4 ), suggesting monkeys preferred to eat inside the forest than in the gardens.

\section{Discussion}

Commensurate with our predictions, samango monkeys used gardens and the ground more extensively during winter, when forest food (indigenous fruit) availability is relatively lower (Wimberger et al. in prep.). Given equal foraging opportunities in the form of artificial foraging patches in both forest and garden habitats, and at positions on the ground and in trees, monkeys decreased their risk-taking behavior, changing their relative use of the matrix by foraging high in trees within indigenous forest. Higher visitation rates to forest patches suggested that monkeys perceived gardens and the ground to be riskier than indigenous forest and tree canopy level.

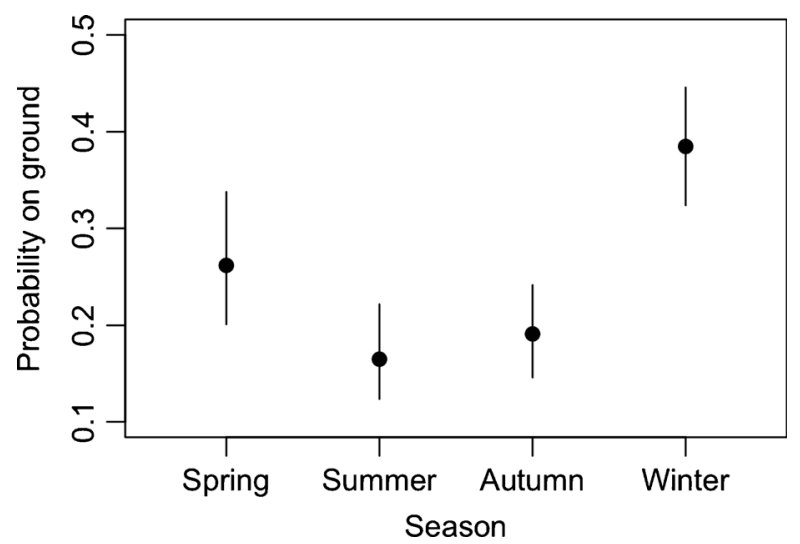

Fig. 2 Mean ( $\pm 95 \%$ CI) proportion of records $(N=13,060$ individual scans) collected during 35 days of group follows during which we observed monkeys on the ground, rather than in trees, across seasons 


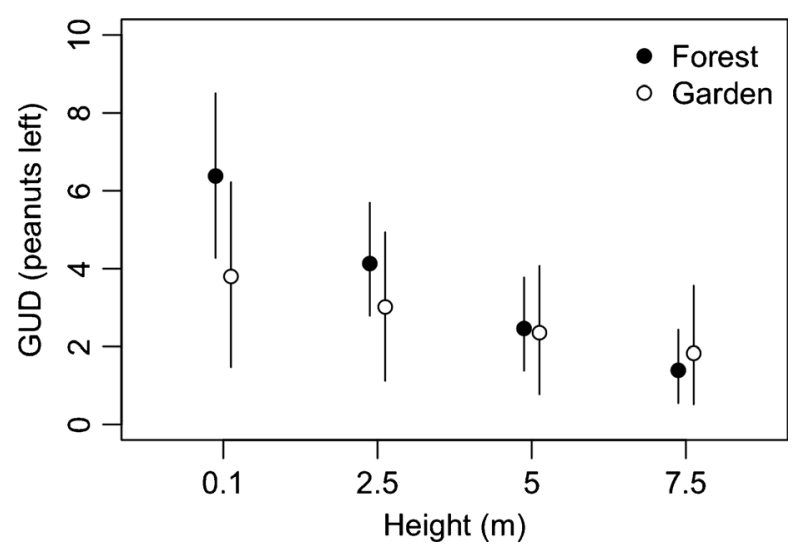

Fig. 3 Mean ( $\pm 95 \%$ CI) GUD (peanuts left uneaten) by height and habitat

However, this difference in perceived risk between habitats was not detectable when we compared the extent to which monkeys depleted peanuts (GUD) on actual visits to our experimental patches.

In the relatively food-rich autumn (Wimberger et al. in prep.), the monkeys' ranges overlapped least with human-modified habitat, yet in the food-scarce winter, they spent most of their time in the village. The monkeys thus made a state-dependent decision, behaving in ways that reduced their risk of starvation while constrained by perceived risks (injury or harm) from humans and domestic dogs. Monkeys faced these risks by foraging on the ground and spending time in a human-dominated landscape, but they

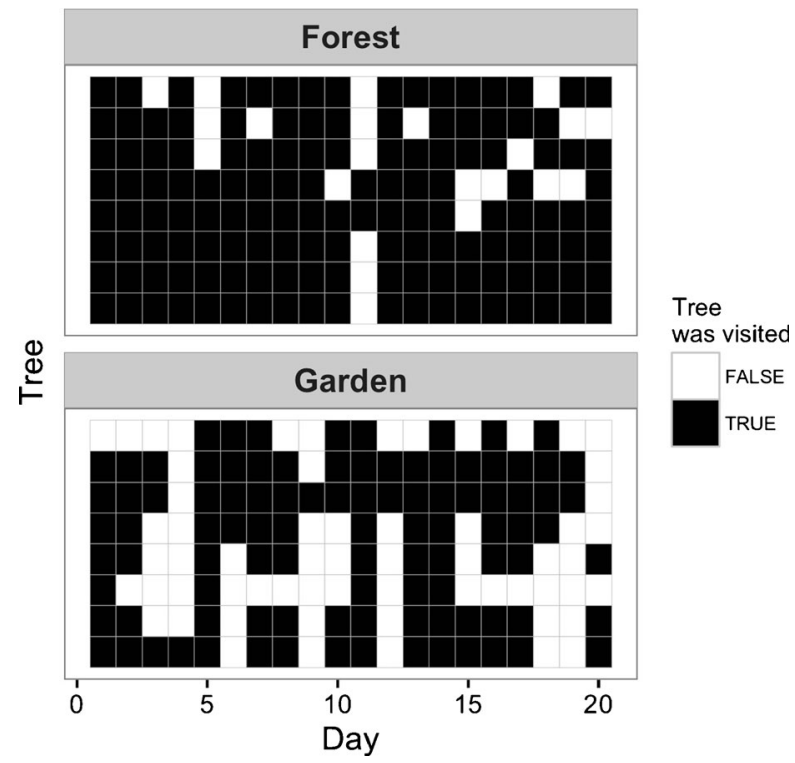

Fig. 4 Monkeys' patterns of visitation to GUD trees by habitat over 20 experimental days (data plotted by individual trees or GUD patches with 8 trees/patches per each habitat) showing that monkeys had higher visitation rates to experimental trees inside the forest than in gardens 
traded off energy intake (from relatively high quality exotic acorns, and later our experimental peanuts) against mortality risk (Lima et al. 1985). Seasonal changes in food availability are likely the primary drivers of monkeys' risk-taking at this extreme southerly site.

As we reduced the risk of starvation in the winter with our GUD experiment (offering high value peanuts in both habitats), we observed a preference (higher visitation rates) by monkeys for safer forest patches in line with our predictions. Furthermore, given food at both ground and tree level, monkeys preferred to forage at less riskier heights above ground confirming findings from similar experiments at a site with high (natural) predatory density (Nowak et al. 2014). Our findings support the theoretical predictions of Sih (1980) that animals will make risk-averse decisions when they can. Our results also indicate that gardens are not inherently "preferred" or favored by monkeys, although exotic seeds are certainly attractive fallback foods (Wimberger et al. in prep.).

For monkeys to persist at this highly seasonal and human-modified site, they have learned to exploit the fallen exotic seeds in gardens during winter months when they are food limited in the forest. Gradually, they have become habituated to anthropogenic disturbance including tree canopy gaps and anthropogenic noise, e.g., radios and chainsaws. This habituation may help explain why monkeys depleted patches to the same extent in the gardens as in the forest once they had already decided to enter gardens.

A recent study on the effects of human noise on ungulates using roadside surveys and observations of elk and pronghorn (Antilocapra americana) along a road corridor in Grand Teton National Park, Wyoming, USA, found that elk were less vigilant and less likely to flee and exhibit defensive behavior with increasing levels of vehicle traffic (Brown et al. 2012). They did however respond to visible moving threats such as pedestrians and passing motorcycles while continuing to ignore the "background noise." This suggests that noise and human activity were not necessarily associated with increased predation risk nor could heightened responsiveness to frequent human stimuli be maintained (Brown et al. 2012). Likewise, monkeys distinguish between different types, levels, and frequencies of anthropogenic risk and respond appropriately (Nowak et al. 2016). Because risk tends to increase as animals move into new areas, monkeys may opt to remain in familiar locations to reduce perceived risk; and, as their experience in an area, e.g., gardens, grows, they may also increase their willingness to exploit patches to higher extents (rather than move to new, potentially riskier, locations). Monkeys did have slightly lower GUDs in the gardens than in the forest, indicating that once they had taken the risk to enter gardens, they ate as much as possible. The relatively higher depletion of garden patches could also be explained by monkeys not moving as much or as far in the gardens given the clumped nature of exotic foods (Wimberger et al. in prep.), as our ranging data show.

Human presence is not always disadvantageous to prey species given that it may come to be associated with lower natural predation risk (Berger 2007; Nowak et al. 2014) as people displace terrestrial predators such as leopards (Isbell and Young 1993). In Hogsback gardens, where dogs pose a real risk, the presence of property owners who like having monkeys in their gardens may confer safety if these people discourage dogs from chasing monkeys. Two monkeys (including one monkey from this group) have been attacked by dogs, while other instances of dogs killing monkeys have been 
reported by Hogsback residents (Wimberger unpubl. data). Accordingly, monkeys may perceive small-scale differences in spatial risk and show preference for certain gardens. People also more readily chase baboons - a probable competitor of samango monkeys at this site - as baboons are seen as dangerous to people and domestic animals more so than the samango monkeys, and samangos may therefore perceive gardens as a "baboon-free" zone. During our GUDs experiments, we observed samango monkeys moving off in complete silence on detecting incoming baboons (while in the forest), suggesting that monkeys were willing to abandon patches of peanuts to avoid baboons.

That monkeys do not generally avoid gardens does not mean that they are not negatively affected, i.e., stressed, or deterred by human presence and disturbance, or that they do not need protection (Gill et al. 2001). Increased commensalism at this site could ultimately adversely affect human-monkey relationships, the physical health of monkeys, e.g., dentition (Tordiffe et al. unpubl. data), and samango monkey population size in Hogsback. Over the past 5 or so years, human-monkey conflict has increased as samango monkeys have ventured more frequently and extensively into residential properties (Wimberger pers. obs.; Wimberger and Bidner 2012). The removal of raked piles of fallen acorns (which represent highly concentrated food patches) and exotic seeds from gardens during winter, as well as covering up rubbish and vegetable gardens, are potential mitigation strategies that could help deter monkeys from gardens (see Wimberger and Bidner 2012 for further recommendations). Long-term solutions will require the gradual phasing out of exotic species that people have planted inside gardens (Wimberger et al., this issue). A concurrent study of monkeys' neophilia (Mathibane 2014) suggested that this same group was more interested in anthropogenic objects, e.g., plastic toys, in the gardens than in the forest. As a consequence, possible intervention strategies aimed at deterring monkeys from gardens may be complicated further by this differential response of monkeys to people and their objects in gardens, which suggests a reduced fear or even elevated neophilia in this relatively novel and fluctuating habitat.

We are optimistic that given improved human understanding of monkeys' habitat choices in Hogsback, and some relatively minor changes in people's habits and maintenance of properties, monkey-human coexistence can be sustained at this highly unusual site where samango monkeys manage risks in a human-modified landscape and endure the pronounced winters at what is the southern limit of their biogeographic range.

Acknowledgments We thank Alison Midgley, Nthabiseng Mathibane, Diana Breshears, Steve Boyes, and Adrian Tordiffe for their assistance in the field. We are grateful to the property owners in Hogsback, especially Storm Haven, Away with the Fairies Backpackers, Mystique, and Hunterstoun, for allowing us access to their gardens to both follow monkeys and carry out our experiment. Support for this work came from the Durham University COFUND, RW Primate Fund, and University of the Free State (K. Nowak); from the Claude Leon Foundation (K. Nowak and K. Wimberger); and UCT URC Fellowship, JMasters NRF Fund, Novartis SAVF Wildlife Research Fund, Primate Conservation Inc., and Mazda Wildlife Fund (K. Wimberger). For GIS support, we are grateful to N. Lindenberg and T. Slingsby from UCT. We thank T. Webster for access and use of his rainfall data and the South African Weather Service (SAWS) for access to their ambient temperature data. We thank the relevant South African authorities from the Department of Economic Development, Environmental Affairs and Tourism, and the Department of Agriculture, Forestry and Fisheries, Eastern Cape Province, for permission to carry out this research. Finally, we thank the guest editors Noemi Spagnoletti, Kimberley Hockings, and Matt McLennan for inviting us to contribute to this special issue of the International 
Journal of Primatology; Joanna Setchell; and also two anonymous reviewers for their helpful comments on our manuscript.

Open Access This article is distributed under the terms of the Creative Commons Attribution 4.0 International License (http://creativecommons.org/licenses/by/4.0/), which permits unrestricted use, distribution, and reproduction in any medium, provided you give appropriate credit to the original author(s) and the source, provide a link to the Creative Commons license, and indicate if changes were made.

\section{References}

Abu Baker, M. A., Emerson, S. E., \& Brown, J. S. (2015). Foraging and habitat use of eastern cottontails (Sylvilagus floridanus) in an urban landscape. Journal of Urban Economics, 18(3), 977-987.

Beale, C. M. \& Monaghan, P. (2004). Human disturbance: people as predation-free predators? Journal of Applied Ecology 41(2), 335-343.

Berger, J. (2007). Fear, human shields and the redistribution of prey and predators in protected areas. Biology Letters, 3(August), 620-623.

Beyer, H. L. (2004). Hawth's analysis tools for ArcGIS. http://www.spatialecology.com/htools

Blumstein, D. (2014). Attention, habituation, and antipredator behaviour: Implications for urban birds. In D. Gil \& H. Brumm (Eds.), Avian urban ecology (pp. 41-53). New York: Oxford University Press.

Brown, J. S. (1988). Patch use as an indication of habitat preference, predation risk, and competition. Behavioral Ecology and Sociobiology, 22, 37-47.

Brown, J. S. (1999). Vigilance, patch use and habitat selection: foraging under predation risk. Evolutionary Ecology Research, 1(1), 49-71.

Brown, J. S., \& Kotler, B. P. (2004). Hazardous duty pay and the foraging cost of predation. Ecology Letters, 7(10), 999-1014.

Brown, J. S., \& Kotler, B. P. (2007). Foraging and the ecology of fear. In D. Stephens, J. S. Brown, \& R. C. Ydenberg (Eds.), Foraging: Behavior and ecology (pp. 437-482). Chicago: University of Chicago Press.

Brown, C. L., Hardy, A. R., Barber, J. R., Fristrup, K. M., Crooks, K. R., \& Angeloni, L. M. (2012). The effect of human activities and their associated noise on ungulate behavior. PLOS ONE, 7(7), 38-40.

Ciuti, S., Northrup, J. M., Muhly, T. B., Simi, S., Musiani, M., et al. (2012). Effects of humans on behaviour of wildlife exceed those of natural predators in a landscape of fear. PLOS ONE, 7(11).

Coleman, B. T., \& Hill, R. A. (2014). Living in a landscape of fear: the impact of predation, resource availability and habitat structure on primate range use. Animal Behaviour, 88, 165-173.

Coleman, A., Richardson, D., Schechter, R., \& Blumstein, D. T. (2008). Does habituation to humans influence predator discrimination in Gunther's dik-diks (Madoqua guentheri)? Biology Letters, 4(3), 250-252.

R Core Development Team. (2015). R: A language and environment for statistical computing. Vienna, Austria: R Foundation for Statistical Computing.

Dalton, D. L., Linden, B., Wimberger, K., Nupen, L. J., Tordiffe, A. S. W., et al. (2015). New insights into samango monkey speciation in South Africa. PLoS ONE, 10(3), e0117003.

Dill, L. M., \& Fraser, A. H. G. (1984). Risk of predation and the feeding behavior of juvenile coho salmon (Oncorhynchus kisutsch). Behavioral Ecology and Sociobiology, 16, 65-71.

Druce, D. J., Brown, J. S., Kerley, G. I. H., Kotler, B. P., MacKey, R. L., \& Slotow, R. (2009). Spatial and temporal scaling in habitat utilization by klipspringers (Oreotragus oreotragus) determined using givingup densities. Austral Ecology, 34, 577-587.

Emerson, S. E., \& Brown, J. S. (2013). Identifying preferred habitats of samango monkeys (Cercopithecus (nictitans) mitis erythrarchus) through patch use. Behavioural Processes, 100, 214-221.

Emerson, S. E., Brown, J. S., \& Linden, J. D. (2011). Identifying Sykes' monkeys', Cercopithecus albogularis erythrarchus, axes of fear through patch use. Animal Behaviour, 81(2), 455-462.

Esri. (2008). ArcGIS 9: ArcMap Tutorial. Redlands: Esri Press.

Frid, A., \& Dill, L. (2002). Human-caused disturbance stimuli as a form of predation risk. Ecology and Society, 6(1).

Getz, W. M., Fortmann-Roe, S., Cross, P. C., Lyons, A. J., Ryan, S. J., \& Wilmers, C. C. (2007). LoCoH: Nonparameteric kernel methods for constructing home ranges and utilization distributions. PLoS ONE, 2(2), e207.

Gill, J., Norris, K., \& Sutherland, W. J. (2001). Why behavioural responses may not reflect the population consequences of human disturbance. Biological Conservation, 97(2), 265-268. 
Hockings, K. J., \& McLennan, M. R. (2012). From forest to farm: systematic review of cultivar feeding by chimpanzees - management implications for wildlife in anthropogenic landscapes. PLoS ONE, 7(4).

Hockings, K. J., Anderson, J. R., \& Matsuzawa, T. (2009). Use of wild and cultivated foods by chimpanzees at Bossou, Republic of Guinea: Feeding dynamics in a human-influenced environment. American Journal of Primatology, 71(8), 636-646.

Hoffman, T. S., \& O'Riain, M. J. (2011). The spatial ecology of chacma baboons (Papio ursinus) in a humanmodified environment. International Journal of Primatology, 32(2), 308-328.

Isbell, L. A., \& Young, T. P. (1993). Human presence reduces predation in a free-ranging vervet monkey population in Kenya. Animal Behaviour, 45(6), 1233-1235.

Lawes, M. J. (1990). The distribution of the samango monkey (Cercopithecus mitis erythrarchus Peters, 1852 and Cercopithecus mitis labiatus I. Geoffroy, 1843) and forest history in Southern Africa. Journal of Biogeography, 17(6), 669-680.

Lawes, M. J. (2008). Cercopithecus mitis ssp. labiatus. IUCN Red List of Threatened Species.

Lima, S. L., Valone, T. J., \& Caraco, T. (1985). Foraging-efficiency-predation-risk trade-off in the grey squirrel. Animal Behaviour, 33(1), 155-165.

Linden, B., Wimberger, K., Ehlers-Smith, Y., Howlett, C., \& Child, M. (2016). A conservation assessment of Cercopithecus albogularis. In M. F. Child, E. Do Linh San, D. Raimondo, H. Davies-Mostert, \& L. Roxburgh (Eds.), The Red List of Mammals of South Africa, Swaziland and Lesotho. South African National Biodiversity Institute and Endangered Wildlife Trust, South Africa

Makin, D. F., Payne, H. F. P., Kerley, G. I. H., \& Shrader, A. M. (2012). Foraging in a 3-D world: How does predation risk affect space use of vervet monkeys? Journal of Mammalogy, 93(2), 422-428.

Mathibane, N. (2014). Neophilia in garden-dwelling samango monkeys. Undergraduate honors thesis, University of the Free State, Qwaqwa, Free State, South Africa

Nowak, K., le Roux, A., Richards, S. A., Scheijen, C. P. J., \& Hill, R. A. (2014). Human observers impact habituated samango monkeys' perceived landscape of fear. Behavioral Ecology, 25(5), 1199-1204.

Nowak, K., Richards, S. A., le Roux, A., \& Hill, R. A. (2016). Influence of live-capture on risk perceptions of habituated samango monkeys. Journal of Mammalogy, in press. doi:10.1093/jmammal/gyw083

Rodgers, A. R., Carr, A. P., Beyer, H. L., Smith, L., \& Kie, J. G. (2007). HRT: Home range tools for ArcGIS, version 1.1. Thunder Bay, Ontario, Canada: Ontario Ministry of Natural Resources, Centre for Northern Forest Ecosystem Research.

Sih, A. (1980). Optimal behavior: Can foragers balance two conflicting demands? Science, 210(4473), 10411043.

Stears, K., \& Shrader, A. M. (2015). Increases in food availability can tempt oribi antelope into taking greater risks at both large and small spatial scales. Animal Behaviour, 108, 155-164.

Strum, S. C. (2010). The development of primate raiding: implications for management and conservation. International Journal of Primatology, 31(1), 133-156.

Tadesse, S. A., \& Kotler, B. P. (2012). Impact of tourism on Nubian ibex (Capra nubiana) revealed through assessment of behavioral indicators. Behavioral Ecology, 23(6), 1257-1262.

Verdolin, J. L. (2006). Meta-analysis of foraging and predation risk trade-offs in terrestrial systems. Behavioral Ecology and Sociobiology, 60(4), 457-464.

Willems, E. P., \& Hill, R. A. (2009). Predator-specific landscapes of fear and resource distribution: effects on spatial range use. Ecology, 90(2), 546-555.

Wimberger, K., \& Bidner, L. (2012). A short guide to living with samango monkeys and baboons in Hogsback. Available at: www.imfene.org/sites/default/files/baboon-interface-resources/living-withsamangos-and-baboons.pdf 